\title{
O discurso dos planejadores na Amazônia e a cultura política de realização
}

\section{The Discourse of Planners in the Amazonian and the Political Culture of Achievement}

\author{
Fernando Arthur de Freitas Neves \\ (D) https://orcid.org/0000-0002-8044-313X \\ Universidade Federal do Pará, Brasil \\ arthurlobinho18@gmail.com
}

Resumo: A justificativa para obter proteção para as elites da Amazônia na expectativa de integração ao modelo desenvolvimento brasileiro pode ser reconhecido no Plano de Emergência da SPVEA. Os planejadores de 1950 seguiram desacreditando as formas extrativistas, enquanto acreditavam na capacidade de intervenção do estado nacional para debelar os entraves. Destacando grandes problemas como educação, saúde, transportes, produção agropecuária e financiamento apontam uma série de medidas para modernizar as relações sociais e econômicas; no entanto, as tentativas sob o vigor do empreendimento capitalista só encontraram sua efetivação com a política de subsídios diretos e de renúncia fiscal da ditadura civil-militar, nas quais as elites regionais tiveram que se contentar com a condição de sócio minoritário, restando mobilizar a denúncia desse projeto enquanto tentava melhorar sua posição nesta empreitada. O corpus de fonte documental para essa investigação está fixado nos discursos das elites sobre desenvolvimento econômico nos Relatório dos governadores do Pará e Amazonas, nas legislações e notícias de jornais jus-

cómo citar: Neves, F. A. (2020). O discurso dos planejadores na Amazônia e a cultura política de realização. Secuencia (108), e1741. DoI: https://doi.org/10.18234/secuencia.v0i108.1741

cc $(1)$ Esta obra está protegida bajo una Licencia Creative Commons Atribución-NoComercial 4.0 Internacional. 
tapostas como um cinerama para justificar o descredenciamento das formas econômicas extrativistas.

Palavras-chaves: história; desenvolvimento; planejamento; elite e território.

Abstract: The justification for obtaining protection for the Amazonian elites in the expectation of integration with the Brazilian development model can be recognized in the Emergency Plan SPVEA. The planners of 1950 continued to discredit extractive forms while believing in the national state's ability to intervene to overcome the barriers. Highlighting major problems such as education, health, transportation, agricultural production and financing point to a series of measures to modernize social and economic relations; nevertheless, attempts under the vigor of the capitalist enterprise only found its effectiveness with the policy of direct subsidies and fiscal renunciation of the civil-military dictatorship, in which the regional elites had to settle for the condition of minority partner, remaining to mobilize the denounce this project while trying to improve its position in this endeavor. The corpus of documentary source for this investigation is fixed in the discourses of the elites about economic development in the Report of the governors of Pará and Amazonas, in the laws and news of newspapers juxtaposed as a cinerama to justify the discrediting of extractive economic forms.

Keywords: history; development; planning; elite and territory.

Recibido: 30 de abril de 2019 Aceptado: 13 de octubre de 2019 Publicado: 12 de agosto de 2020

\section{INTROITO}

s proposições sobre o desenvolvimento da Amazônia merecem um trata-
interpretação constante revisitação para poder compreender as dinâmicas de 
buições feitas fora das fronteiras do Brasil, como bem assinalam os trabalhos em torno da Pan-amazônia. ${ }^{1}$

O contributo da expressão Formação Social deve ser mobilizado como ferramenta metodológica para aclarar as possibilidades de explicação sobre como a estrutura de produção de bens está articulada às relações de tessitura social em movimento para empreender a satisfação de reprodução dos sistemas. Marx (1991) inaugurou o debate sobre as formações econômicas pré-capitalistas. Inspirados nesse conceito, existem muitos outros estudiosos dissecando as propriedades dessa ferramenta. Para efeito de esclarecimento, uso aqui a maneira indicada pelo autor ao identificar linhagens, ou se preferirem, relações de força, integrando diversas e potenciais capacidades articuladas sobre a produção material da existência das sociedades. Isto significa dizer que a Amazônia é compósito de uma série de experiências diferenciadas, às vezes coeva, de produzir a si mesma. É nosso intuito, portanto, captar como essas formas de organizar e representar a si própria foram tecidas e interpretadas à luz dos elaboradores que se debruçaram sobre o Plano de Emergência e o Plano Quinquenal da década de $1950 .^{2}$

Kelerson Costa (2009, pp. 1-25) ao propor uma série de apontamentos sobre a formação histórica da Amazônia brasileira indica vários modos de ocupação, com durações diferenciadas em tempos e territórios, manifestando a existência de conhecimento sobre a ecologia do lugar e a consolidação

${ }^{1}$ O desflorestamento do território amazônico de Colômbia, Peru e Brasil foram mitigados se comparado com a expansão desenfreada da década de 1970, porém ainda permanecem uma série de conflitos na questão do uso da terra, deficiências técnicas na gestão dos sistemas ecológicos, bem como o problema do uso e propriedade da terra das muitas populações tradicionais em conflito com as sociedades nacionais. Esta discussão do desenvolvimento regional aparece, às vezes, como sendo um avesso e/ou complemento dos respectivos estados, ou uma singularidade desse território. Convêm perceber o imaginário sobre essa região partilhada na Pan-amazônia e os discursos elaborados desse universo multifacetado e polissêmico. Ver Anderson (1990); Buelvas, Jost e Flemes (2012); Eden (1994, pp. 55-66); Parodi (1982, pp. 107-114); Pizarro (2004).

${ }^{2}$ Inicialmente, houve o Programa de Emergência, lançado em 1954 (Superintendência da Valorização Econômica da Amazônia [spvea]). Posteriormente, o Plano Quinquenal (1955) guardava as características de uma extensão formal do primeiro, prosseguindo no objetivo de alterar percurso até então existente. Em ambos há uma sinergia que reflete a necessidade de uma intervenção consistente para instalar reformulação da estrutura produtiva, dissecando em diversos eixos, desde a agricultura até indústria, passando pelos problemas do financiamento, da ausência de medidas profiláticas no combate de doenças, e a necessidade firmar o homem na Sociedade Rural por um projeto educacional com esse objetivo. Esta é uma ação coordenada pelo Estado Nacional para governar a região. 
dessas ocupações enquanto existiram; porém descredenciando esses arranjos devido à baixa integração com a sociedade nacional, gerando um quadro bastante imperfeito sobre ao que costumeiramente se tem apropriado como formação histórica. Seu alvo está nas circunscrições da Amazônia Ocidental, porém é bem mais extenso.

O extrativismo há muito se constitui um modo de produção fecundo na Amazônia, sem porém gozar de prestígio pela sociedade erigida com os ideais de ilustração, graças à incomoda sujeição imposta pela natureza como uma determinação de per se. A economia mercantil não tinha esses melindres, compreendia bem a riqueza representada pelos produtos engendrados nesta estrutura e deles aproveitava todos os insumos como "Cacáu, Castanha, Couros verdes salgados, Ditos secos salgadas espichados, Ditas de refugos ditos ditos, Gomma elástica, Grudes de peixe, Óleo de cupahyba, Peles de veado, Piassava, salsa, urucú em massa, Diversos" são algumas das peças descritas no Relatório de Presidente da província de 1870 (p. 33), recorrentes dentre tantos outros documentos oficiais para tempos anteriores e ulteriores.

Voltando um pouco mais atrás, no século XVII abundava um conjunto de fortificações para controlar o fluxo das chamadas drogas do sertão e ao mesmo tempo serviam de barreiras à concorrência de ingleses, holandeses e franceses (Reis, 1984; Tavares, 2011). Cacau, baunilha, cravo, canela, anil e raízes aromáticas estão relacionados nas séries de correspondências grafadas no período, sendo referidas como parte vital para assegurar o interesse dos dominadores portugueses, naquele instante, como testemunha a historiografia.

Houve outra demanda significativa para assegurar o domínio português na região, manifesto no apresamento de indígenas para manutenção perene da atividade de coleta das drogas do sertão como assinala Chambouleyron (2006). O domínio indígena da ecologia daqueles sertões foi peça relevante para viabilizar a efetiva ocupação, e sobre este esteio foi alicerçado a empresa das missões religiosas carmelitas, franciscanos, mercedários e jesuítas.

Há um consenso estabelecido quanto à existência de uma política colonial mais centralizada quando da intervenção de Pombal, como ministro, colocando termo às iniciativas estrangeiras até então correntes. Para assegurar o domínio nas esferas política, militar, religiosa e econômica, o estado coesionou sua intervenção. Sobre a estrutura montada para reger o mando no Estado do Grão-Pará e Maranhão em 1751 tomo de empréstimo o dialogo travado sobre as rupturas e permanências dos governo que se sucederam a partir da análise feita por Chambouleyron (2006), citando uma respeitável 
bibliografia sobre força de trabalho, escravidão, agricultura, estado, sociedade e economia.

Podemos perceber o juízo de supremacia da agricultura sobre o extrativismo, no próprio Chamboleyron ao sustentar a tese "Plantações, sesmarias e vilas. Uma reflexão sobre a ocupação da Amazônia seiscentista” enfatiza como o empreendimento particular buscou se assentar nestas terras, domesticando produtos de coleta em artigos da lavoura como foi o caso do cacau; contestando a afirmação de Alden sobre o estigma extrativista inerente à amêndoa até a metade dos setecentos.

É tempo de revisitar essa sentença e colocar em xeque a perspectiva do estabelecimento da política pombalina como sendo a gestão por excelência da dominação portuguesa fundada na agricultura. Não é à toa a validação da agricultura feita por Alexandre Rodrigues Ferreira ao indicar os avanços e recuos da mesma nestes sertões, enquanto lutavam com os indígenas resistentes à civilização e ao trabalho agrícola (Raminelli, 1998, pp. 157-182). O complexo estruturado do extrativismo vegetal e animal tinha um vigor econômico que se interpunha como concorrente às medidas tidas como civilizatórias. A disciplina mobilizada em torno da agricultura, tanto quanto a introdução do conhecimento necessário à execução dessas tarefas, subtraia tempo e esforço das formas de produção extrativistas desenvolvidas pelos indígenas, além de permanecerem protagonistas no domínio sobre o trabalho.

Com efeito, a historiografia desconsiderou na política colonial o quantum de saber havia em extensão e profundidade na economia das drogas do sertão, jamais podendo ser resumido ao momento da coleta. Esse equívoco perdura e esteve presente no diagnóstico feito pelos planejadores nos 1950 quando tentaram alterar, uma vez mais, as bases da economia da região. $O$ Plano Quinquenal inflexionou em parte a acidez desta crítica presente no Plano de Emergência, embora o horizonte tenha continuado sendo a agricultura em substituição ao extrativismo. O diagnóstico recorrente é o desprezo por esse último, percebido como mera força auxiliar da colonização, sem ver nessa atividade uma organização própria; sem se restringir a uma mera articulação da economia local à economia mercantil em expansão; antes, representava uma combinação de conhecimento e produção ordenados na apropriação e domínio da ecologia do lugar, estrutura potencializada para converter-se em ativo de troca, portanto, riqueza da economia extrativista em escala, sendo inserida a uma economia mundial. É tempo de fazer uma crítica a essa percepção colonialista, pois ela se tornou não apenas depreciativa, tanto quanto 
denega o protagonismo existente por aqueles que se encontraram, ainda que mediados por tensões e cumplicidades na realização do complexo do extrativismo da formação social na Amazônia. ${ }^{3}$

\section{ADEUS EXTRATIVISMO}

O extrativismo gozou de pouco prestígio devido às oscilações no que respeita a quantidade da oferta e a qualidade do produto, sempre estando aquém do que desejava a proto cadeia do aviamento, afetado pelas condições climáticas, território (floresta de terra firme e áreas alagadas), transporte, controle sobre a mobilização da força de trabalho e a concorrência com produtos já firmados. As muitas tentativas de administrar toda a cadeia das chamadas drogas do sertão podem ser percebidas no investimento em conhecer, eleger quais desses produtos poderiam vir a se tornar objeto de cultivo, bem como os ganhos a serem auferidos como estas escolhas, como atesta a domesticação do cacau por centenas de anos. Esta amêndoa vigorou com bastante aceitação, sendo inclusive utilizado como mediador de trocas.

Extrações de quinina e de borracha são similares para retratar o processo de incorporação de produtos da floresta à mundialização da economia, embora esses empreendimentos não tenham alcançado uma perspectiva de desenvolvimento autônomo, ainda assim representam expressivas tentativas de assegurar minimamente a retenção da riqueza conquistada com a produção feita pela cadeia do extrativismo. Os oitocentos cristalizaram a complexidade dessa cadeia com a incorporação da Borracha à segunda revolução industrial nos seus mais diferentes usos, até alcançar a condição de componente fundamental na indústria de pneumáticos.

Convém assinalar o destino que ambas tiveram ao perder a centralidade de acumulação de riqueza na Amazônia devido aos mecanismos de usurpação, tão correntes aquela época, por meio do sequestro de sementes e mudas, cultivadas em outros territórios para promoverem a produção em grande escala via modelo plantation, abandonando o lócus de produção origi-

${ }^{3}$ Algumas pistas para captar essas interpretações, ver Ferreira e Bastos (2016). Contudo, a noção do primado da região sob o estado nacional eu não subscreva, trata-se de análise robusta sobre os impasses do desenvolvimento Amazônia. Digno de nota é a própria explicação de um dos idealizadores da crítica ao desenvolvimento manifesto por sua própria pena (Reis, 1955). 
nal, contribuindo para a debacle dessas estruturas, contudo, não significou o fim do complexo do extrativismo compreendido desde a extração/coleta, regatão/aviamento, financiamento internacional.

Fronteiras externas e internas estiveram se deslocando muito intensamente na virada do XIX e Xx. Elas também foram objeto de intensa vinculação com a extração da borracha. O caso mais representativo, sem dúvida, foi a ocupação do território que se converteu no Acre para o Brasil à custa da Bolívia, mas também patenteia a mobilização interna com as frentes de expansão de extração da goma elástica (Aragão, 1989, pp. 219-227). Na Calha Norte da América do Sul não foram diferentes os procedimentos para assegurar as ocupações dos chamados territórios vazios, pois ao mesmo tempo serviram de justificativa para definir os limites entre os países na Amazônia. As frentes de expansão internas foram responsáveis pela compressão dos territórios ocupados por indígenas, enquanto urdia um processo de desestruturação de seu modo de vida. Esses territórios passaram a integrar a cesta de terras a serem ocupadas pela fronteira em movimento. Se o extrativismo não foi abandonado por essas populações, o controle já estava sob o domínio da cadeia de aviamento.

Os arranjos de integração das atividades econômicas propiciadas pela goma elástica faz com que possamos indicar uma matriz comum, circunscrevendo a formação social na Amazônia, dinamizando para além dos traçados das fronteiras nacionais, fundado na estrutura reprodutiva do complexo do extrativismo, tal como descrevemos de maneira concisa como extração/coleta, regatão/aviamento até o financiamento internacional.

Após a crise iniciada em 1912 com crescente perda da renda da economia da borracha, tornou-se evidente a dificuldade de estabelecer um mecanismo eficiente de manutenção da valorização da extração de matéria-prima. Entretanto, a alternativa sugerida continuou a validar a agricultura como único modelo de efetiva rentabilidade, aliado à promoção da civilização, enquanto desqualificava a vertiginosa contribuição do extrativismo na formação social amazônica.

Esta crítica ao extrativismo animal/vegetal continuou presente no decorrer do século $\mathrm{xx}$, sugerindo a necessidade de uma intervenção potente para domar de vez as riquezas da floresta, utilizando a modernização do campo, pela via da agricultura e da pecuária, sob o impulso da empresa capitalis- 
ta, em detrimento da vitalidade do extrativismo como se pode reconhecer no complexo da economia da castanha-do-pará. ${ }^{4}$

Certa historiografia brasileira fez uma análise sobre a paridade entre a importância da borracha e do café existente na virada do séculos XIX e xx, porém destaca-se uma primazia na articulação promovida pelo café com toda a rede de indústria, comércio e finanças como assinalou Wilson Cano (1984); porém não foi menos pujante a cadeia econômica desenvolvida pelo extrativismo/aviamento no qual estão arrolados bancos, estrada de ferro, navegação e mesmo um setor de indústria vinculada à borracha (Mourão, 1989).

Ainda durante os anos 1930, na gestão do paraense Lyra Castro no Ministério da Agricultura, Industria e Comercio percebe-se a orientação de efetuar a lavoura como uma referência no Pará, situação documentada nos estudos para criação do Centro Agrícola Ingles de Souza na cidade de Monte Alegre, instituto com vocação para o desenvolvimento da agricultura. Nesta senda, o Serviço de Inspeção de Fomento Agrícola Federal, dirigido à época pelo engenheiro Enéas Pinheiro, forneceu só naquele ano $10355 \mathrm{~kg}$ de sementes, plantas forrageiras e cereais a 127 agricultores no Pará, criadores e industriais; embora não informe sob qual método foi concedido o benefício, suponho faziam parte do clientelismo ou de algum cadastro nessa repartição do ministério. Havia em andamento, segundo a Mensagem enviada pelo governador do Pará à Assembleia, inquéritos profissionais sobre seringueira, camuru, fumo, castanha, feijão, cana-de-açúcar, coqueiro, balata, andiroba e madeiras, além do incentivo para a fruticultura em associação com a Sociedade de Fruticultura de Belém. ${ }^{5}$

Este esforço seguirá ao longo dos anos para converter o extrativismo em agricultura, combinado com o fortalecimento das ações de investimento público no auxílio à produção agropecuária, na montagem de Estação Meteorológica, Estações de Pesquisa Experimental, Serviço Industrial Pastoril, realizando uma gama de experimentos e auxílios técnicos para suportar os reclamos de maior amparo ao setor agropastoril do Pará, complementado pelo

${ }^{4}$ Além de alimento, a castanha gerou novos produtos no ramo dos cosméticos. Em recente tese de doutorado observa-se a trajetória da castanha-do-pará apoiada no extrativismo e os processos decorrentes de suas relações como a concentração de riqueza, tanto quanto as constantes derrubadas da floresta que tem colocado limite a capacidade de reprodução dessa atividade (Almeida, 2017).

${ }^{5}$ Mensagens do governador do Pará para a Assembleia (PA), 1930, pp. 121-124. 
Posto de Assistência Veterinária com raio de ação do Marajó até o Tapajós. ${ }^{6}$ Desnecessário dizer ser difícil o atendimento nessa escala.

Entre os anos 30 e 40 do século xx não há nenhuma menção ao termo extrativismo nos jornais de grande circulação no Pará, já o termo agricultura sobressai com grande impacto anunciando a necessidade de carregar maiores inversões para desenvolver a região. No estado do Amazonas foi mencionado nos jornais apenas uma única vez o termo extrativismo nessas duas décadas, referindo-se como esta atividade estava sendo transformada, graças a Associação Comercial do Amazonas, ${ }^{7}$ por meio de um programa de ações no intuito de colaborar para propagandear e melhor colocar os produtos no sul do país e no exterior, combinando esta ação com assistência à produção chamada de "nativa" como sinônimo de extrativismo, aliada à produção agrícola propriamente dita. ${ }^{8}$

Uma tentativa das elites do norte em dar resposta à perda de influência e prestígio do extrativismo, de maneira assertiva, considerou-se dois produtos, Borracha e Castanha; o primeiro em franca decadência, embora com os seus usos em alta na economia mundial, não deixava de despertar interesse; enquanto o segundo, não tendo a relevância do primeiro para os usos da química da segunda revolução industrial, comportava uma receita respeitável, sobretudo ao fazer parte do consumo da Europa e Estados Unidos. O estado do Amazonas pautou esse tópico na agenda do governo Vargas com a criação do Instituto Federal da Borracha e da Castanha, demanda representativa da região, emulava o Instituto do Cacau na Bahia, e outros como os do açúcar e álcool, laranja e algodão, sob a supervisão do Ministério do Trabalho, Indústria e Comércio. Chegou a ter um anteprojeto elaborado, porém sem maior apoio, não logrou êxito. ${ }^{9}$

Em 21 de março de 1935 o Jornal do Brasil noticia que foram conciliados os interesses do Amazonas e do Pará pela criação do referido Instituto. As chamadas classes interessadas, por intermédio da Associação Comercial do Amazonas e da Comissão de Propaganda do Comércio Exterior, junto ao Interventor do Pará, à época liderada pelo Major Magalhães Barata, reconhe-

${ }^{6}$ Mensagens do governador do Pará para a Assembleia (PA), 1930, p. 126.

${ }^{7}$ Hemeroteca nos jornais no Pará e Amazonas no período.

${ }^{8}$ Assembleia Legislativa do Estado do Amazonas: Mensagem apresentada pelo presidente, 1936, p. 203.

${ }_{9}$ Assembleia Legislativa do Estado do Amazonas: Mensagem apresentada pelo Presidente, 1936, p. 207. 
ceram ser uma proposta à altura do desafio de impulsionar região. Na exposição de motivos à presidência da república, Agamenon de Magalhães, titular do Ministério do Trabalho, alega a necessidade de amparar a inciativa coordenada pelos próprios interessados, Amazonas, Pará e o território do Acre, para racionalizar e aproveitar "a exploração da indústria extrativa da goma elástica e da colheita periódica das castanhas" conectando de modo favorável crédito, transporte e outras facilidades. A notícia sobre borracha e castanha as insere como ramos da indústria amazônica, envolvendo aqueles "empenhados na compra, venda, e beneficiamento" para logo a seguir confirmar o sentido que se quis imprimir de uma atividade econômica pujante em acordo com a expectativa principal de "arrancar a indústria extrativa da tremenda e prolongada crise em que se debate, há longos anos, em franco caminho do aniquilamento [...] a da castanha, possibilidade de melhores dias pela remoção dos fatores que the perturbam o ritmo normal do comercio". ${ }^{10}$

De uma vez só, extrativismo e agricultura são tornados invisíveis, sobressaltando apenas a circulação da mercadoria ao denominar essa atividade nos marcos exclusivos da indústria, embora fique evidente a expressão extrativista da borracha e da castanha, conformando o conjunto da cadeia como um complexo do extrativismo, atingindo até o financiamento.

Outrora, 377.000:000\$000 foi o valor gerado pela exportação de borracha, enquanto o café atingia 385.483:000\$000, portanto são equivalentes em importância e escala. Em 1910, esta quantia demonstra quanta riqueza fora gerada, mas logo depois da concorrência asiática, caiu vertiginosamente o produto do norte; uma das questões levantadas era devido ao modelo de coleta continuar a utilizar as "estradas de seringa" considerando a distribuição natural das árvores, enquanto a disposição do plantio, como era nas colônias inglesas e holandesas, assegurava maior oferta de seiva, situação a ser superada com a criação do Instituto como menciona na argumentação. Outro fator limitante foi a acusação de prática extorsiva existente em Belém e Manaus no processo de financiamento feito pelas casas aviadoras; diversamente da situação ocorrida na Ásia, onde a produção dos concorrentes já estaria fundada em bases científicas, tendo vantagem de abundância de capitais e mão de obra barata. ${ }^{11}$

${ }^{10}$ Jornal do Comércio, 13 de outubro de 1935, p. 1.
${ }_{11}$ Jornal do Comércio, 13 de outubro de 1935, p. 1. 
Diante da real ameaça da concorrência da borracha da Ásia, sobremodo porque os diferentes usos que estavam sendo dados à goma elástica assinalavam a expansão de sua utilidade convertendo em novas fábricas, gerando aflição pela possível perda de protagonismo nessa economia. O Congresso Nacional aprovou a lei 2543, ainda em 1912, cujo fim seria aportar um plano para a "indústria do extrativismo" ameaçada, estabelecendo a necessidade de incentivar o cultivo das espécies em Estações Experimentais, desenvolvimento do transporte fluvial e terrestre; fixação definitiva de trabalhadores, dito de outra maneira, imobilização da força de trabalho; acesso ao crédito e melhoria nas condições de vida que eram lastimáveis nos seringais onde campeavam doenças tropicais.

Lei aprovada, porém não implementada, segundo o articulista, copilando o Ministro Magalhaes, devido à falta de condições financeiras e a extensão demasiada do plano, ficando apenas indicado a necessidade de "extinguir" os serviços de aviamento. Malgrado as dificuldades da borracha com preço em queda no mundo da década de 1930, as qualidades da borracha nativa não deixaram de ter apelo, justificando, portanto, a iniciativa para a constituição do já mencionado Instituto.

A necessária incorporação de tecnologia faria bem ao produto amazônico para ganhar mais mercado, sugerindo rever o método tradicional a ser incorporado às manufaturas, suprimindo lavagem e secagem lenta que fazia o produto amazônico perder peso. Também aponta o declínio efetivo com a crise que já se arrastava há muitos anos, conforme anunciou o Ministério da Indústria, comprometendo pela via da criação do Instituto o fornecimento e medidas para sanear técnica e financeiramente a atividade. Com efeito, o governo federal por esta iniciativa realinhou seu compromisso pela "Criação do aparelho resguardado da estrutura Econômica da Amazônia."12

Sem comprometer propriamente os cofres da União para o sustento do Instituto, foi indicado um empréstimo de 20.000:000\$ frente ao Banco do Brasil para que fossem montados todos os serviços. Ao adquirir autossuficiência, a economia da borracha e da castanha poderiam pagar o principal e os juros daí decorrentes. Como garantia, a melhora do preço e as muitas necessidades que a nova indústria apresentava tornava a oferta da mesma imprescindível, sendo importante fazer este investimento para suprir o Instituto.

\footnotetext{
${ }^{12}$ Jornal do Comércio, 13 de outubro de 1935, p. 1.
} 
Quanta à Castanha era muito menos volumoso o argumento para a criação do Instituto, porém o estado assimila a defesa de ser a única região fornecedora desse produto e quer manter a boa aceitação nos Estados Unidos e Europa. Atribui uma receita ainda diminuta à falta de organização econômica das coletas e do comércio. Em complemento, de maneira incisiva, relata ser grave o problema do financiamento ser monopolizado pelas empresas importadoras, com suas sedes em Belém e Manaus, sem outro financiamento para fazer concorrência.

Os discursos confirmam uma predileção e um sentido para a indústria da goma elástica, no entanto fica patente a subalternidade da categoria do extrativismo, e não há nenhuma referência quanto à verticalização da indústria da borracha, o mesmo vale para castanha. Por quase 20 anos não houve uma intervenção mais ousada, nem mesmo o Banco da Borracha ou o Fundo Constitucional do Norte alavancou uma alteração de rumo.

\section{CONFERIR EXECUÇÃO AO PLANO QUINQUENAL}

Significava convencer a nação de que se tratava de um esforço nacional para assegurar a ocupação nos chamados "espaços inaproveitáveis do território", para uma valorização da região como um "empreendimento de vulto". Este foi o primeiro signo de justificação para constituir uma sociedade economicamente estável. Na época não há ainda a preocupação com a noção de sustentabilidade no uso dos recursos naturais. Expresso esse primeiro eixo, a riqueza gerada atenderia as demandas sociais, pelo menos nesse discurso naturalizado de distribuição de riqueza com a oferta de oportunidades. De modo suplementar, a economia da Amazônia deveria se integrar ao complexo em edificação do parque industrial brasileiro pela criação do Programa de Emergência como uma projeção ao primeiro Plano Quinquenal.

Populações dispersas ao longo dos rios e florestas, assentadas no extrativismo, deveriam partilhar na nova realidade com a recepção de migrantes para poderem gerar arranjos econômicos novos. $O$ planejamento erigido à condição de sujeito, ditando critérios de eficiência econômica e ocupação sobre territórios; induzindo atividades de comunicação e transporte; circunscrevendo zonas propícias à agricultura, à indústria e pecuária, bem como indicando a necessidade de melhor aproveitar zonas marginais da estrada de ferro de fronteira e reconhecer a relevância de navegação de longo curso; além 
de identificar as áreas da frente pioneira de expansão a penetrar na Amazônia devido à abundância do estoque de terras, segundo o diagnóstico sobre a condição das terras devolutas.

Se anteriormente a penetração foi ditada pelos rios, doravante, esta não seria mais a única opção. Foi do interior da terra firme que pulsou a nova penetração. Não por acaso a construção da rodovia Belém/Brasília assumiu a dianteira na mobilização de esforços materiais e espirituais para obter o sucesso desejado. As barreiras ecológicas e topográficas perderam a capacidade de deter o avanço da fronteira.

De modo bastante agressivo, as antigas trilhas de comunicação da economia mercantil cederam lugar à integração por rodovia, particularmente durante a construção da malha rodoviária na virada dos anos 50 para os anos 60. O traçado da Belém/Brasília serviu para solidificar o contato com a principal cidade da Amazônia, no caso, Belém. Porém era importante espraiar essa intervenção até outro centro dinâmico, de modo a tornar mais vasto o projeto de articulação do Estado Nacional sobre o território; fazendo com que o poder de estado fosse capaz de gerar emprendimentos volumosos, agregados à lógica de desenvolvimento do mesmo. Essa intervenção irá posteriormente ser sufragada na constituição da Zona Franca de Manaus; outras capitais e cidades na região sofreram, ao menos sazonalmente, alguma intervenção para justificar essa dinâmica de integração e crescimento econômico, sem necessariamente ensejar um modelo de distribuição de riqueza em escala incrementado pela entrada do grande capital.

Decerto, era preciso reabilitar áreas que já haviam comportado diferentes modos de produção, articulados de forma subordinada ou marginal na formação social da Amazônia, congregando estruturas tradicionais aos empreendimentos tipicamente capitalista, sem entretanto promover a indústria de bens de capital. Premissa para atrair as elites políticas regionais em seus próprios interesses subordinadas à economia nacional.

As chamadas zonas recuperáveis descritas foram eleitas para abrigar iniciativas concernentes à dinâmica do Plano Quinquenal (sPVeA, 1954, p. 5), indicada nos setores, tais como produção de alimentos, produção de matéria prima e indústria, aplicação de capital, transporte e comunicação, energia, saúde e nível cultural. Partindo da ideia de incrementar a produção de alimentos fazia todo sentido, porque de modo obsessivo os planejadores viam na agricultura uma forma civilizatória de combate ao extrativismo. No entanto, nem sempre fora assim. Ruth Burlamarqui de Moraes (1984) dissertou so- 
bre os dramas da agricultura para poder concorrer com o modelo extrativista empregado na Amazônia durante o período de maior influência da borracha. Sua análise sobre séries demográficas demonstra como as correntes migratórias para região foram bastante afetadas pelas condições de extração do látex nos seringais.

A referência sobre os investimentos em agricultura são mais intenções do que propriamente uma política de fixação do homem na terra, pois o esforço maior da força de trabalho de colonos/imigrantes acabava sendo reduzido à máxima de servir ao seringal no início do século $\mathrm{xx}$, havendo inclusive penas severas quando os seringueiros tentavam diversificar a produção em culturas adjacentes às estradas de seringa. Isso não significa desconhecer a existência da agricultura, embora esta tivesse um prestígio moral elevado, economicamente era degradada diante da contínua valorização do extrativismo (Moraes, 1984).

Dispostos a não repetir erros passados, pensam os planejadores poder realizar uma introdução de tecnologias de melhoramento através da organização de colônias para ampliar a oferta da produção de alimentos, devidamente orientados pela assistência de agrônomos, cuja meta a ser alcançada em primeiro lugar seria a autossuficiência alimentar, seguida da produção de matéria prima para a economia regional, nacional e internacional. Amparados em muitos preconceitos, os planejadores investem contra a cultura local, denunciando a valorização dos hábitos alimentares fundados no ancestral consumo da farinha de mandioca, um obstáculo, segundo creiam, a ser depurado da tradição, pois atribuíam a baixa eficiência nutricional dessa prática, em desacordo com a modernização alimentar do início da década de 1940. Contra tomar leite com farinha de mandioca, como era comum na Amazônia, tornou-se campanha dos arautos do progresso no intuito de erradicar esses velhos costumes (Muniz, 2013). Josué de Castro, estudioso da fome, subscreveu esta tese junto a outros planejadores.

Aumentar a importância do gado suíno, bovino, caprino e aves, mas sem mencionar o gado bubalino, bastante expressivo no Marajó e no Médio e Baixo amazonas consta nas prioridades do Plano de Metas, bem como toda a estrutura sanitária inerente aos empreendimentos dessa natureza. Convém salientar, àquela altura não se tinha ainda instalado um palco de luta aberta pela terra como se revelou com a escalada de violência produzida depois na década de 1970. O estoque de terras parecia inesgotável e a noção da pecuária como vetor de desenvolvimento parecia se impor, a exemplo do ocorri- 
do na expansão do Centro-Oeste; mas nos Planos de 1954 e no de 1955 não há nenhuma menção à estrutura fundiária, reforma agrária, ou ao histórico mecanismo de acesso e firmação de posse da terra; esta situação foi alterada profundamente quando os grandes projetos se impuseram na região e convulsionaram o quadro de ocupação na Amazônia.

De modo quase incidental menciona a necessidade de produção de peixes. A organização desse setor na forma moderna delimita projeto, estrutura e objetivo, algo inexistente nos planos quanto a essa matéria. De todo modo, a pesca não estava invisível como assinalava o jornal Liberal de 11 de junho de 1951. Encontra-se registro, por exemplo, no Baixo Amazonas, no município de Porto de Moz, integrando subsidiariamente às atividades agrícolas e pastoris; sempre com a persistência da extração da borracha; entrementes, quanto à agricultura, não restava dúvida, o produto principal continuava sendo a plantação de mandioca. Sobre a pesca há menção ao uso do Timbó, tecnologia indígena extrativista, fartamente utilizada em algumas regiões da Amazônia.

Os pescadores do Pará estiveram ativos no ano de 1951 para defender seu ponto de vista frente aos problemas do setor. Quanto às ameaças ao alimento básico da população paraense, reivindicam ao governo do estado alguma proteção para continuarem seu ofício de pesca. Eles representavam perto de 12000 pescadores inscritos em colônias, cujo meio de vida requeria atenção, em consonância ao objetivo de fornecimento de alimento à população. Um exemplo de obstáculo para a atividade foi o encarecimento do utensílio de pesca mais elementar, a linha de pescar, essa sofreu uma subida vertiginosa de 30 cruzeiros para 100 cruzeiros. A pesca na forma industrial ainda não havia estabelecido concorrência com a pesca artesanal, por isso o problema mais grave era o fio de linha de pescar.

A produção de matéria prima é um capítulo sempre carregado de valorização moral. De maneira sub-reptícia diz respeito ao enunciado de uma suposta fragilidade, ou mesmo a completa ausência de um pendor para desenvolvimento da indústria devido a carga hereditária de indígenas; senão quando realizam a produção extrativista, por exemplo, de borracha, de castanha e de juta associadas à cadeia de produção existente no país. No tocante à inversão de capital, na prática manifesta a ausência de uma acumulação suficiente na região, capaz de fazer alavancar a formação social da Amazônia para um moderno complexo produtivo industrial. Curiosamente, o aviamento chamado no Plano Quinquenal de "adiantamento" é reconhecido como um sistema. Trata-se do método histórico utilizado pelo capital mercantil 
para conseguir financiar a empresa econômica. Isto resulta no levantamento de mercadorias e dinheiro no valor equivalente à produção na expectativa de poder pagar com o resultado da coleta/safra.

Destarte, foi sinalizada a necessidade de gerar um mecanismo de financiamento capaz atender a esses reclamos, via expansão de crédito bancário, destinado ao homem do interior para servir de suporte ao esforço de produção, tanto quanto a importância de incentivar o capital privado a investir na participação de empresas rurais criadas dentro desse perfil. Para o primeiro quinquênio foi dimensionado 200 milhões de cruzeiros oriundos do Fundo de Fomento à Produção do Banco de Crédito da Amazônia.

Estabelecer permanentemente a comunicação e transporte foi um veio rico desenhado na estratégia de valorização do Plano Quinquenal; assim justificaram a criação de um sistema de transporte regular na calha do Rio Amazonas; na verdade esse argumento acabou por desconhecer o expediente da navegação a vapor em curso desde a década de 1850, embora tenha perdido a importância para o transporte de borracha, nunca deixou de crescer, permanecendo ativo para circulação de mercadorias e pessoas. Benchimol (1995) relata a forte expansão do transporte fluvial a vapor, devidamente subvencionado desde a segunda metade do oitocentos durante o império, mecanismo também utilizado na república. Anteriormente as embarcações à vela levavam doze dias entre Belém e Manaus, enquanto os barcos a vapor levavam apenas quatro dias. Segundo o balanço do Tesouro Público do Pará do ano de 1929 , a navegação gerou uma receita de 147:130\$450, porém ocasionou uma despesa de 197:237\$530, demonstrando ser deficitária a operação. Ferreira-Neto (1974) localiza na década de 1950 o momento de passagem para supremacia do transporte rodoviário sobre o transporte ferroviário e a navegação de cabotagem e fluvial.

De maior relevância no Plano foi a tese de criar ligações com as outras regiões do Brasil por via terrestre. Isto foi justificado para assegurar o deslocamento das populações das regiões já saturadas, tanto quanto tornaria propício o estabelecimento de praças comerciais no interior da Amazônia. Se a rodovia secundarizou a navegação, nem por isso os rios deixaram de ser utilizados como via de comunicação ligando esses interiores. Pelo estado nacional, uma empresa pública foi encarregada de adquirir equipamentos a aperfeiçoar o transporte via Serviço de Navegação de Administração de Portos do Pará (SNAPP), perfazendo uma frota maior de navios, portos, flutuantes e rebocadores. Apesar da perspectiva dos planejadores, decididamente, a opção 
pela navegação sofreu forte redução com apenas $7000 \mathrm{~km}$ dos $20000 \mathrm{~km}$ navegáveis na Amazônia, somente começando alterar essa trajetória muito posteriormente.

Sem qualquer demonstração para efetivar a ligação por via terrestre, os Planos de Emergência e o Quinquenal não mencionam o volume de capital, de mercadorias ou de pessoas a transportar; de outro lado, o investimento em ferrovia já não vinha sendo praticado; a navegação seguiu secundária como possibilidade de aproveitamento da rede existente. A opção por rodovia quis validar a imposição física do domínio sob o território, tornando a navegação um ente marginal nos sobredito planos. Por via rodoviária o excedente de força de trabalho, liberado pelo esgotamento das formas de apropriação nas outras regiões, seria atraído na expectativa de acesso à terra; por exemplo, os despossuídos ou expulsos no Nordeste em busca de novas áreas atravessando o Vale do Gurupi ao Norte; bem como daqueles oriundos do Sudeste ao antever um território para assentar propriedade, quando em Minas Gerais, Bahia e Goiás não mais era possível, em vista disso seriam atendidos por uma ligação entre Belém e Anápolis. Outra rodovia de penetração seria o caminho em paralelo ao Rio Tapajós, oferecendo uma ligação entre Cuiabá e Santarém, além da conexão via terrestre para o Oeste, entre Cuiabá/Porto Velho.

Para região do Baixo-Amazonas a perspectiva era suprir a comunicação por uma estrada de rodagem entre o norte de Óbidos a ligar os campos do Ariramba e do Urucuiana, região já familiarizada com a criação de gado. Esta opção poderia trazer bons frutos para fomentar o desenvolvimento local, supunham. A necessidade desta medida foi anunciada na obra de Gastão Cruls (1938) A Amazônia que eu vi: Óbidos-Tumucumaque destacando um trajeto de aproximadamente quatrocentos quilômetros, enquanto no Plano Quinquenal é proposto apenas sessenta quilômetros, deixando de responder a efetiva necessidade da obra indicada. De Oriximiná até Cipoal seria completada a estrada de 40 quilômetros. O grosso do investimento em estada de rodagem seria Belém/Anápolis, depois batizada como Belém/Brasília, todavia a integração para acima do Rio Amazonas não pôde dispor de mais recursos para ligar este território à banda ocidental. Posteriormente, ao final da ditadura civil-militar, portanto, fora do escopo desse estudo, a configuração do Projeto Calha Norte visou absorver esta região, devido às pressões para proteção de terras indígenas, às críticas pelo autoritarismo do projeto, somados aos custos, serviram para bloquear essa iniciativa. 
Percebido como entrave, as questões referentes à saúde foram indicadas no Plano Quinquenal. Embora o receituário replique o imaginário do "inferno verde", sempre apontando o clima quente e úmido, com muitas chuvas, enormes reservas de águas paradas, criando condições para proliferação de insetos e das moléstias transmissíveis, coloca para si a tarefa de ordenar o serviço de saúde. O remédio seria a construção de uma política sanitária, reconhecendo o problema da falta de saúde como uma faceta de um problema econômico e de educação. Somente através de uma reforma a alcançar o aumento de produtividade da riqueza e de distribuição de renda se poderia responder a demanda de saúde, grafaram os planejadores.

Concentrar esforços nos serviços básicos de saneamento e esgoto, abastecimento de água, melhoria de condições higiênicas, especialmente nas habitações da zona rural, amparado no serviço de assistência médica-sanitária, hospitais gerais e maternidades, rede de postos de saúde nas localidades onde não houvesse nenhum equipamento de saúde. O estado nacional deveria promover rotineiras campanhas contra doenças transmissíveis tais como malária, tuberculose, esquistossomose, doença de Chagas, filariose, brucelose, leishmaniose, tracoma e parasitose em geral; cuidar da infância por meio da atenção especial aos lactantes, às gestante e alimentação pré-escolar e escolar; lembra o Plano da necessária introdução do iodo no sal de cozinha para o combate ao bócio; além de investimento em pesquisa de modo a confrontar a incidência de doenças, aumentando o conhecimento dos órgãos de controle para orientar a profilaxia e tratamento das mesmas. Estas ações seriam coroadas com o monitoramento de um serviço de estatística e educação sanitária a gerar insumos para adoção de políticas públicas.

Sobre os entraves ao desenvolvimento na década de 1950, Charles Wagley, antropólogo americano, estudioso da Amazônia, também cumpriu a função de dirigente na divisão de Serviço Especial de Saúde Pública (SESP). Essa parceria foi montada entre os Estados Unidos e o Brasil de modo assistir aos aliados com apoio técnico na área de saúde, tanto quanto na área econômica para os produtores de matérias-primas estratégicas. Nunca se deve desconsiderar a importância dada à borracha. Nessa oportunidade, este autor reuniu materiais para abastecer sua reflexão a respeito do homem nos trópicos, sendo publicado Amazon Town em 1956. Na trilha dos estudos quanto ao desenvolvimento, descreve o clima; aborda a economia de extração de látex e o peso representativo da pesca numa comunidade amazônica; a vigência do sistema de aviamento; a relação de sociabilidade e a estratificação social, 
mistura de raças, relações de compadrio para assegurar alianças; o universo de crenças resistente à modernização e a vitalidade da medicina popular em seus conflitos com a medicina científica; concluindo como de costume com a ratificação da tese de valorizar a técnica para redimir a Amazônia, sobrepondo à tradição. ${ }^{13}$ Obviamente os proponentes do Plano estão em acordo com esse prognóstico de imprimir desenvolvimento, salvo honrosas vicissitudes na tradição.

Os planejadores encarregados de apresentar alternativas ao desenvolvimento autóctone, alertam para a diferença gritante entre a educação adquirida pelas classes superiores das grandes cidades e a precariedade da educação ofertada nos sertões da Amazônia. Na prática, a referência à educação superior, a qual apenas as elites tinham acesso, salvo exceções, compreendia a cultura de graduar bacharéis, sem dispor de maior opção de formação técnica em conexão com o mundo do trabalho de 1950, já suplantado o quadro do período conhecido como substituição das importações.

Contrastando com a formação das elites, influenciados por uma noção utilitária, os planejadores buscaram manter os alunos do campo, no campo, aproveitando a sua cultura de trabalho para fortalecer este nexo com proposições educacionais, orientadas para tornar mais eficiente a produção agrícola, alterando o perfil do baixo nível técnico da agricultura na Amazônia. A esse diagnóstico seguia a intenção de preservar o espírito da sociedade tradicional dos trabalhadores do campo, pois identificavam nesses um ideal desprovido da contaminação da educação formal assentada nos hábitos e valores urbanos. Por isso esse investimento cujo fim era a formação profissional centrada nas demandas da sociedade rural, em contraste com a formação citadina, vocacionada para profissões liberais e comércio.

As classes superiores formadas nas cidades não tinham nenhuma vocação para atender as necessidades do interior, embora os planejadores tenham percebido a constituição de um segmento de classes médias graças a essa educação superior, não propuseram alguma alternativa para incorporá-las em suas metas. Logo, a proposta redentora para aumentar o nível cultural do interior não deveria copiar o modelo educacional da cidade, mas sim forjar um modelo voltado para educação no campo, atento às necessidades de fixar

13 Nessas outras obras podemos captar uma percepção da Amazônia por um estrangeiro que encontrou-se com esse ambiente. Wagley (1957, 1972, 1974, 1976). 
homens e mulheres, fortalecendo a cultura rural por meio de uma modernização conservadora.

Para compreender como as populações do interior persistiam na região era necessário a elaboração de uma estratégia de valorização econômica. Desconsiderar os acertos e erros poderia tornar uma vez mais infrutífero a tarefa de "civilizar" este ambiente. Somente profissionais moldados nesse espírito seriam capazes de reconhecer e oferecer uma instrução especificamente dirigida a esse ambiente, trazendo maior possibilidade de êxito.

Para os planejadores, as falhas das ações de modernização estavam na reprodução do paradigma educacional utilizado nas cidades. As propostas de alfabetização junto às populações do interior fracassaram exatamente por não reconhecerem essas diferenças. Por sua vez, não identificaram a importância da falta de continuidade e de recursos financeiros para prover educação e saúde ao interior. Para eles, os profissionais atualizados nessa nova pedagogia de considerar o ambiente poderiam superar os limites anteriores por não contarem apenas com a formação das letras e números; antes, esses profissionais teriam uma bagagem cultural, assentada no universo do campo, capaz de nutrir os processos educativos com o componente de ruralidade.

Seria fundamental perceber a fragilidade das próprias classes dirigentes na região ao pretender apontar uma alternativa de desenvolvimento. Acostumadas a defenderem seus privilégios para asseverar suas propriedades e os mecanismos de extração de renda, pouco informaram sobre um modelo de desenvolvimento autóctone, isso tornou-se mais agudo no segmento educacional. Coube aos planejadores propor um novo corpo de professores e educadores em geral. Destituídos de formalismos, estes deveriam interligar-se aos processos culturais do ambiente amazônico no intuito de alterar o estado da arte; dar importância à investigação sobre como a região estava sendo percebida por aqueles que mantinham contato forçosamente pelo deslocamento da fronteira, embrenhando-se cada vez mais na floresta.

Outro arranjo institucional foi desenhado sobre a escola tradicional. Denominados Missão Cultural Rural e Centro Social Rural, composto por uma pequena equipe de educadores especializados seriam deslocados aos povoados mais afastados. Cada Missão teria médico, agrônomo, assistente social, podendo ser ampliada, de acordo com a necessidade, por enfermeiros, dentistas, veterinários e, especialistas em indústrias do campo ou artesanias. A Missão deveria selecionar e preparar os educadores para atuarem nos Centros Sociais Rurais. A cada Centro corresponderia um casal, o homem 
na função de professor, já a mulher continuaria na lida com as crianças. $\mathrm{Na}$ equipagem do Centro, uma pequena oficina de costura e outros instrumentos necessários às indústrias rurais. No fim de semana, o Centro seria convertido em clube de recreação, espaço de reuniões, em dias normais, voltava a funcionar como escola. ${ }^{14}$

Ambicionando mudar a mentalidade do território rural, encarregavam-se de difundir ensinamentos a partir dessa roupagem nova, acrescentando no ensino elementar a atualização das técnicas do trabalho agrícola. De modo adicional seria fundada uma escola de pesca para potencializar essa atividade. Tudo isso dentro da lógica de combinar a dinâmica do trabalho do campo com o aprendizado no Centro Social Rural.

Reconhecendo as diferenças regionais, a Amazônia para poder integrar-se de fato ao enredo nacional de desenvolvimento econômico e cultural, reclamava o aporte de mais uma instituição que formasse quadros técnicos para servirem de alavanca às invenções orquestradas no Plano Quinquenal. A constituição de uma universidade como fonte de produção de conhecimentos novos era uma imposição para poder ter sucesso a estratégia de valorização da região, pois as faculdades existentes não retinham suporte para alterar a trajetória estabelecida. A formação de profissionais liberais atendia ao interesse da elite, embora desvinculada do horizonte de desenvolvimento postulado. Formar especialistas técnicos vocacionados para intervir na realidade, montando arranjos produtivos no interior era uma meta de longo prazo traçada pelos planejadores.

$\mathrm{Na}$ ausência de técnicos para responderem às demandas, o Plano indicava a importância de investir em cursos intensivos para as de profissões como tratorista, telegrafistas, mecânicos, enfermeiros, eletricistas ou aquelas em conformidade com os projetos a serem implantados. Contudo o Plano não é apenas instrumental, ao menos não de todo, reconhece a importância de alargar a experiência dessas populações do interior ao propor a criação de mais bibliotecas e museus, onde pudessem encontrar e manusear acervos no suporte papel ou filmes documentários que tornassem mais rápida a assimilação da informação.

As expectativas consagradas no Plano Quinquenal são amplas, embora tenham o mérito parcial de perceber como o desconhecimento dos vários ambientes que compõem a região foram parte dos equívocos cometidos nas

${ }^{14}$ Para aprofundar, ver Silva e Batista (2016, pp. 56-72). 
estratégias anteriores de desenvolvimento, terminam por sucumbir ao desejo de integração ao eixo nacional. Não concebiam a possibilidade alternativa de desenvolvimento autóctone, graças à estrutura das mentalidades existente em secundarizar as formas de economia extrativistas associadas à agricultura tradicional.

\section{PLANEJADORES CAÇANDO RESULTADOS}

Se o chamado planejamento científico se revestiu de um diagnóstico cujo fim foi extrair um conjunto de linhas mestras sobre as quais deveria atuar o governo central do Brasil, sobretudo ao ser alçado como o sujeito por excelência a promover o desenvolvimento na região amazônica, os resultados foram pífios; no entanto não se pode lhe descredenciar a iniciativa. Ao ler o Plano Quinquenal se observa a estratégia de valorização da ciência, tendo por Altar Mor -o planejamento, como técnica introdutória da razão, ao enfatizar maior relevância à investigação de modo a se aproximar da realidade.

Preciso e detalhado, foi considerado como um rito de passagem entre a sociedade tradicional, assentada no extrativismo, para a adaptação à sociedade industrial moderna, supostamente incorporando técnicas específicas para o ambiente do trópico úmido. Segundo os planejadores seria necessário investimento progressivo na educação profissional, de tal forma que ela fosse um esteio junto à construção de conhecimentos básicos para fortalecer o ingresso de maior capital, ao qual se pretendia dominar em nível cultural.

A excelência da inteligência da Amazônia foi envolvida nesse projeto de construir o horizonte, como fica assinalado pela sua composição presidida por Artur César Ferreira Reis, seguida de Francisco Pereira da Silva, Sócrates Bonfim, Ricardo Borges, Waldir Bouhid, Firmino Dutra, Francisco Custódio Freire, Stélio Maroja, Raul Valdez, Jaime Vasconcelos, Armando Storni, Francisco de Paula Vicente Pinheiro, Valério Caldas de Magalhães, Cid Rojas Américo de Carvalho.

Este documento é uma preciosidade ao trazer a necessidade do planejamento como passo primeiro de sucesso da intervenção estatal ativa até 1959. A efetivação do golpe de 1964 aprofundou significativamente a concepção de uniformidade na Amazônia por via da Superintendência de Desenvolvimento da Amazônia (SUDAM), erigida sobre o substrato da SPVEA em 1966. Durante a ditadura civil-militar vários órgão complementares foram criados 
para dar suporte a estratégia de modernização conservadora. Ao porto livre da Zona Franca de Manaus, foi estabelecida em 1967 a Superintendência da Zona Franca de Manaus (suframa), para implantar um polo industrial.

Essa lógica de estatuir organismos no formato de superintendências de desenvolvimento regionais (Superintendência do Desenvolvimento do Nordeste [Sudene], Superintendência do Desenvolvimento do Centro-Oeste [SUDECo] e Superintendência do Desenvolvimento do Sul [SUDESUl]) assinalava uma tentativa de centralizar a gestão do desenvolvimento do governo federal; portanto, essa medida representou a acolhida das críticas feitas pelas elites das regiões quanto à falta de apoio para o desenvolvimento regional.

Anteriormente o chamado abandono do território e das populações da região, cedeu lugar à ostensiva intervenção política do estado para viabilizar a ocupação por colonos nas terras cortadas por estradas, gerando maior exclusão das populações tradicionais formadas por caboclos, indígenas, quilombolas e ribeirinhos. Desta forma, o estado fomentou as condições para tornar mais conflituosa a região amazônica. Loureiro e Pinto demonstram como essas ações foram legalizadas, sem considerar o histórico de ocupação das populações que já estavam secularmente na região (Loureiro e Pinto, 2005, pp. 77-98). Embasados por instrumentos legais que asseguraram títulos aos novos ocupantes, a face do conflito recrudesceu graças a opção do estado em não prover medidas de assentamento, considerando os antigos direitos de ocupação. Essa situação prosperou com a chegada de migrantes após as construções das primeiras estradas de longo curso, como a Belém/Brasília nos anos cinquenta.

Sem dúvida o projeto liberal havia ficado para trás. Se o chamado Estado Novo buscou efetivar um pacto com a nação, sob o signo da mobilização populista, o retorno à democracia representativa compreendeu a necessidade de incorporar os territórios da fronteira à dinâmica desenvolvimentista. Euclides da Cunha no início do século já havia denunciado a condição de abandono em que viviam as populações da Amazônia, chegando afirmar "O seringueiro é, obrigatoriamente, profissionalmente, um solitário”. Contra essa forma de ocupação, o estado vai intervir, procurando adensar a população nos territórios de modo a conferir um aumento da atividade econômica, segundo os cânones da modernização conservadora.

O estado brasileiro magnificava suas conquistas com a fundação de cidades e vilas na Marcha para Oeste, abrindo cada vez mais a fronteira, impulsionando a migração, estabelecendo colônias de agricultores, abrindo estradas e expandindo a produção pecuária. 
Convém assinalar que os sentidos dessa brasilidade ganhou maior relevo com essa intervenção de unir a Amazônia ao conjunto do Brasil, depois de realizada a sobredita marcha, embora sofrendo muitas mediações entre o poder central, representado pelas políticas de industrialização acelerada em processo no sudeste, por um lado, e as críticas da elite regional, particularmente concentrada em Belém e Manaus, por não se vê contemplada nessa modernização conservadora, ratificando a noção de colonialismo interno, por outro.

Depois do boom da borracha, as elites da floresta observaram um definhar de sua modernização em contraposição ao que ocorria no sudeste. Isto porque o pacto federativo entronizado na primeira república permitia um amalgama de interesses autônomos dentro da federação. Com este pacto colocado em cheque pela crítica à sociedade liberal e a configuração de uma centralização política no/pelo estado brasileiro, a região assistiu uma subordinação dessa intervenção pela composição de novos interesses emanados a partir do poder central, externados na figura dos interventores do Estado Novo.

Quando eclodiu a segunda guerra mundial, a possibilidade de retomada mais efetiva de concordância entre a elite da região amazônica e o poder central do Brasil pareceu ter renovada chance. Anteriormente, a iniciativa em Forlândia, área de produção de borracha da Ford \& Conpany (Freitas e Neves, 2017, pp. 244-266), para constituir um espaço frente à borracha asiática sob controle dos japoneses, inscreveu-se numa lógica própria de concorrência dos monopólios da indústria gomífera, não obstante a guerra tenha forçado um entrosamento destas circunstancias.

Descrita como a Batalha da Borracha, um microuniverso do conflito mundial, também signo na mitologia da saga nacional como parte da incorporação da região no esforço de conformação da identidade do país, representa o compromisso de superar a relação da mesma como mero apêndice (Guillen, 1997, pp. 95-102). Por consequência desse despertar, os defensores de uma revitalização amazônica ganharam audiência, atestando o fim da era de esquecimento e de marginalização. A convicção deste instante apegava-se ao esteio de brasilidade promovido pela economia nacional, agregando as contribuições da região à modernização nacional.

O encurtamento das distâncias entre as regiões foi feito pelas estradas de rodagem construídas durante o período da ditadura militar, todavia as frentes pioneiras continuavam a infiltrar-se nas ilhargas da fronteira perseguindo o rastro de novas terras, secundariamente, garimpos movimentavam-se; posteriormente os grandes projetos de mineração assumem a liderança 
ao serem apoiados pelo estado nacional. Se, a princípio o roteiro do desbravamento apropriava-se das trilhas históricas de penetração, em meados do século xx depreende-se uma dispersão de investidas para além dos traçados dos rios, tornando mais complexa a abrangência e o reconhecimento da fronteira. O signo de seguir em direção ao oeste sintetiza esse aprofundamento do estado que se quer nacional, rompendo a tradição como tal até então vivenciada somente pelos marcos fronteiriços. Internamente, significava uma conquista do território para viabilizar política e simbolicamente a brasilidade.

Os ocupantes das novas terras trouxeram um novo modo de perceber a floresta e o meio ambiente, calcado na diferenciação, no estranhamento e decisivamente na acepção de conquista. Porém, esse traço da frente camponesa em expansão demonstrava as contradições capitalistas quando se vê expulsa de suas terras, obrigando-os a alargarem a fronteira.

Embora a frente camponesa também tenha uma faceta própria sobre os conflitos internos, foi contra o grande capital (nacional ou transnacional), e o estado propriamente dito que mobilizou uma intelligentsia composta de articulistas de jornal, profissionais liberais, eruditos e políticos. Um consenso mínimo serviu de plataforma para desancar críticas públicas nos jornais sobre modo como a Amazônia era tratada; nesses testemunhos constava a progressiva contestação sobre o Norte entregue a sua própria sorte, enquanto uma vez mais o sudeste banqueteava-se com a prosperidade, fruto de esforços aqui construídos.

Orlando Moraes, um jornalista, foi um dos polemistas mais contundentes, conseguindo representar a Amazônia contra a política nacional que parecia privilegiar as ações de afirmação de domínio político sobre o território, em vez de salvaguardar o desenvolvimento econômico da região. Segundo este, por exemplo, a instalação de guardas e postos militares avançados nas fronteiras, deveriam ser financiadas com os recursos do estado nacional e não com os recursos oriundos dos 3\% constitucionais. Essa característica de uma reserva da fronteira não explorada adquire o caráter de reserva de valor, sob a qual o estado pretende resolver o problema do estrangulamento da fronteira do sudeste, em vias de fechamento e, as áreas de tensão já em ebulição em cursos no nordeste; enquanto anunciava uma forte ação racionalizadora a ser entregue ao grande capital para triunfar sobre as tentativas tradicionais que não conseguiram tirar a região do "atraso".

Destarte, a noção de uma terra estrangeira na consciência nacional, como aparece em Alfredo Ladislau; a Amazônia como inferno verde, em Al- 
berto Rangel; o ultimo capitulo de gêneses, de Euclides da Cunha, traduzem o estupor com que a região é afigurada. Esses testemunhos convocados por Orlando Moraes são retratos que teriam perdidos sua validade pelo despertar de uma força renovadora de novos empreendimentos a serem financiados com os 3\% constitucionais.

O Plano de Valorização da Amazônia colocado a cargo da sPVEA deveria estimular as vocações potenciais existentes para poder integrar-se aos investimentos de infraestrutura, oportunidade de expandir as forças de economia homogeneizada pelo capitalismo. Ao lado da SPVEA, o Banco de Crédito suportaria a montagem dessa infraestrutura, complementando a necessidade de dinamizar o setor produtivo da região para grande escala, desse modo rompendo a inércia.

Este foi o instante de exacerbação do conflito entre a região e o estado nacional, pois as formações econômicas que concorreram com o capitalismo já consolidado não suportaram os preços da produção de uma economia em escala, como a que ocorria no sudeste. Além de não poder contar com os mecanismos usuais de proteção, a elite regional denúncia como setores capitalistas já consolidados se beneficiam dos financiamentos dos 3\%. Do mesmo modo, esses arranjos constituídos alhures, graças a sua força centrípeta drenaram a riqueza líquida da região, ressuscitando o velho fantasma da economia da borracha, cuja batuta estava em favor do capital transnacional dos pneumáticos. Receavam sofrer de modo idêntico com o desmantelamento das formas tradicionais de extrativismo já engendradas outrora.

Contudo, o estado nacional não pode prescindir de criar uma estratégia de intervenção para região, daí, chama para si a responsabilidade de vencer a floresta, através da alteração das formas tradicionais de propriedade e posse existentes no seringal, no castanhal, no guaranazal, e numa faixa de terras de ocupação de sitiantes, além das áreas de indígenas que conseguiam sobreviver enquanto não foram irrompidas pela fronteira, para a propriedade privada capitalista da terra, tornando secundário a patronagem, o aviamento, o regatão e todo circuito da economia mercantil.

O peso destas derrotas não retraiu o espírito do jornalista, sempre pronto a acoimar o estado, reconhecendo, entretanto, a relevância prestada por alguns de seus organismos na região. Pretendia-se inverter o sentido do baixo desenvolvimento usando as prerrogativas conquistadas em 1946. Na década de sessenta, a Superintendência do Desenvolvimento da Amazônia (SUDAM) e Banco da Amazônia (BASA) são apresentados por Orlando Moraes como 
instituições pertinentes para induzirem desenvolvimentos, a exemplo do roteiro seguido pela região vizinha amparada na SudEnE e Banco do Nordeste.

Por seu turno, o "Sul", como nomeava o crítico, estava interessado em sufocar o regime de favorecimento alcançado pela Amazônia na arena nacional, tentando submeter metas, segundo os interesses prioritários da "plutocracia do sul" em detrimento dos interesses da economia regional. Os estados de São Paulo, Rio de Janeiro, em alguma medida, Minas Gerais, viram confirmados seus interesses, resultando no investimento de infraestrutura, considerando o histórico protecionismo daquela região por estar mais presentemente próxima ao núcleo de poder, situação bastante denunciada por aqueles a experimentar a periferia.

Exatamente quando o país consegue se debruçar sobre o modelo de desenvolvimento, a região norte, marginal como outras regiões brasileiras, protagoniza um rearranjo que pretende superar o isolamento através da construção da estrada rodoviária Belém/Brasília. Mais uma vez, o inconformado Orlando Moraes assacará o vilipendio sofrido pelos 3\% do Fundo Constitucional que financiou a construção da estrada, em vez de ser sustentado pela contribuição da região Sul. Na prática, a abertura da Belém/Brasília tão somente serviu para abalar ainda mais a produção regional devido à concorrência dos produtos por ali chegados, descredenciando o produto regional, enquanto infundida um novo modelo de consumo e de produção.

Opondo-se abertamente a essa postura "dominadora", Orlando Moraes combateu com as armas que tinha, embora ainda não conseguisse propor organicamente uma estratégia de integração da Amazônia no projeto nacional. Tarefa essa que seria elaborada sob o terror do regime de exceção, guardando seus próprios modos de validação, como foi o caso do Núcleo de Altos Estudos Amazônicos da Universidade Federal do Pará.

A academia na Amazônia embora tivesse uma história similar a outras do Brasil, só vai se especializar na crítica sobre desenvolvimento após não conseguir encontrar eco para incorporar a perspectiva regional no projeto nacional. O planejamento será a ferramenta para retificar esse estado de subsunção, pois através deste, a intelectualidade da região procurou criticar o ordenamento cujo fim era fazer da Amazônia a Redenção do país.

A criação de institutos de $\mathrm{P} \& \mathrm{D}$, dotados de massa crítica para elaborar essa inserção, motivou um rico debate sobre os modos de operar o desenvolvimento. Inicialmente, consoante as projeções da elite regional, a intelectualidade destes institutos legitimou o desejo de progresso à custa das riquezas 
energéticas, minerais e florestais; entretanto, logo percebeu os descalabros provocados com a investida do grande capital ao alijar ainda mais as antigas elites do progresso material e espiritual tão requerido. Perseguindo caminhos para além dessa experiência de modernização conservadora, esses centros de estudos de desenvolvimento forjaram uma crítica a este modelo, porém somente com o fim da ditadura civil-militar podemos testemunhar uma vigorosa renovação teórica e prática sobre propostas de desenvolvimento.

\section{REFERENNCIAS}

Almeida, J. J. (2017). A Castanha do Pará na Amazônia - Entre o Extrativismo e a Domesticação. Jundiaí: Paco Editorial.

Anderson, A. B. (ed.) (1990). Alternative to desforestation: steps toward sustentainable use of the Amazon Rain Forrest. Columbia University Press: Nova York.

Aragão, M. B. (1989). Ainda a Amazônia. Cadernos de Saúde Pública, 5(2), 219-227.

Benchimol, S. (1995). Navegação e transporte na Amazônia. Manaus: Edição Reprográfica.

Buelvas, E. Pastrana, Jost, S. e Flemes, D. (eds.) (2012). Colombia y Brasil: isocios estratégicos en la construcción de Sudamérica? Bogotá: Editorial Pontificia Universidad Javeriana/Fundación Konrad Adenauer/German Institute of Global and Area Studies (GIGA)/Universidad San Buenaventura.

Cano, W. (1984). Desequilíbrios regionais no Brasil: alguns pontos controversos. Em L. G. de M. Belluzo e R. Coutinho (orgs.), Desenvolvimento capitalista no Brasil: ensaios sobre a crise. Instituto de Economia-Universidade Estadual de Campinas.

Chambouleyron, R. (2006). Plantações, sesmarias e vilas. Uma reflexão sobre a ocupação da Amazônia seiscentista. Nuevos Mundos Mundos Nuevos. Dor: https://doi. org/10.4000/nuevomundo.2260

Costa, K. S. (junho, 2009). Apontamentos sobre a formação histórica da Amazônia: uma abordagem continental. Série de Estudos e Ensaios/Ciências Sociais/Flacso-Brasil, 1-25. Recuperado de http://flacso.org.br/?publication=apontamentos-sobre-a-formacao-historica-da-amazonia-uma-abordagem-continental

Cruls, G. (1938). A Amazonia que eu vi: Obidos, Tumucumaque. Rio de Janeiro: Companhia Editora Nacional (Brasiliana, vol. 113. Bibliotheca Pedagogica Brasileira).

Eden, M. J. (1994). Environment, politics and Amazonian deforestation. Land Use Policy, 11(1), 55-66. 
Ferreira, S. M. P. e Bastos, P. P. Z. (2016). As origens da política brasileira de desenvolvimento regional: o caso da Superintendência da Valorização Econômica da Amazônia (spvea). Instituto de Economia/unicamp, Campinas (Texto para Discussão, 266). Recuperado de http://www.eco.unicamp.br/docprod/downarq. php?id=3461\&tp=a

Ferreira-Neto, F. (1974). 150 anos de transportes no Brasil 1822/1972. Brasília: Ministério dos Transportes.

Freitas, D. e Neves, J. (2017). Fordlândia: o empreendedorismo inovador da Ford Motor Company na Amazônia brasileira. Revista Gestão \& Tecnologia, 17(3), 244-266. DoI: https://doi.org/10.20397/2177-6652/2017.v17i3.1237

Guillen, I. C. (1997). A batalha da borracha: propaganda política e migração nordestina para a Amazônia durante o Estado Novo. Revista de Sociologia e Política, 09, 95-102. Recuperado de https://revistas.ufpr.br/rsp/article/view/39301/24120

Loureiro, V. e Pinto, J. (2005). A questão fundiária na Amazônia. Estudos Avançados, 19(54), 77-98. Recuperado de http://www.revistas.usp.br/eav/article/view/10071

Marx, K. (1991). Formações econômicas pré-capitalistas. São Paulo: Paz e Terra.

Moraes, R. B. de (1984). Transformações demográficas numa economia extrativista Pará (1872-1920). (Dissertação de Mestrado). Universidade Federal do Panará, Brasil.

Mourão, L. (1989). Memória da indústria paraense. Belém: Federação das Indústrias do Estado do Pará.

Muniz, É. S. (24-31 de julho, 2013). ¡Coma con leche y sin harina! Nutrición, raza y políticas sociales en Brasil (1940-1960). (Trabalho apresentado). Embodied Politics: Race, Sexuality and Performance (Políticas Corporales: Raza, Sexualidad y Performance), Tepoztlán, Morelos, México: Institute for Transnational History of the Americas.

Parodi, J. L. (1982). A Peruvian experience for the development of Amazonia: the regional development organization of Loreto (Ordeloreto) and the Jenaro Herrera Settlement Project. Em Amazonia, Agriculture and Land Use Research: Proceedings of the International Conference (pp. 107-114). Cali, Colombia: Centro Internacional de Agricultura Tropical.

Pizarro, A. (2004). Hispanoamérica y Brasil: encuentros, desencuentros, vacíos. Acta Literaria, 29, 105-120. DoI: http://dx.doi.org/10.4067/S0717-68482004002900007

Raminelli, R. (1998). Ciência e colonização: viagem filosófica de Alexandre Rodrigues Ferreira. Revista Tempo, 6, 157-182.

Reis, A. C. F. (1984). As fortificações da Amazônia no período colonial. Revista do Instituto Histórico e Geográfico Brasileiro, 344, 217-227. 
Reis, A. C. F. (1955). Fundamentos, história, estrutura e funcionamento da SPVEA. Brasil: Escola Brasileira de Administração Pública.

Silva, J. B. da e Batista, I. M. S. (2016). O $1^{\circ}$ Plano Quinquenal de Valorização Econômica da Amazônia de 1955: Educação para o Desenvolvimento Amazônico. Revista Histedbr On-Line, 15(66), 56-72. DoI: https://doi.org/10.20396/rho.v15i66.8643702 SPVEA [Superintendência, de Plano de Valorização. Econômica da Amazônia]. Plano Quinquenal e Concepção Preliminar da Valorização Econômica da Amazônia. Belém: Setor de Coordenação e Divulgação, 1954.

Tavares, M. G. (2011). A Amazônia brasileira: formação histórico-territorial e perspectivas para o século xxi. GEOUSP Espaço e Tempo, 15(2), 107-121. Recuperado de http://www.revistas.usp.br/geousp/article/view/74209

Wagley, C. (1957). Uma comunidade amazônica: estudo do homem nos trópicos. São Paulo: Companhia Editora Nacional (Biblioteca Pedagógica Brasileira. Brasiliana, vol. 290).

Wagley, C. (1974). Man in the Amazon. Gainesville, FL: University of Florida.

Wagley, C. et al. (1972). Race and class in rural Brazil. Nova York: Russell \& Russell.

Wagley, C. et al. (1976). Amazon town. Londres: Oxford University Press. 